\title{
COMISSÃO PRÓPRIA DE AVALIAÇÃO (CPA): SIMILARIDADES E DESSEMELHANÇAS NO USO DA ESTRATÉGIA NA EDUCAÇÃO SUPERIOR E EM ESCOLAS DO ENSINO FUNDAMENTAL
}

\author{
Mara Regina Lemes De Sordi* \\ Recebido: 23 nov. 2010 \\ Aprovado: 26 mar. 2011
} * Professora Dra., da Faculdade de Educação da UNICAMP, Departamento de Estudos e Práticas Culturais
(DEPRAC), pesquisadora do LOED, Campinas, Brasil. E-mail: maradesordi@uol.com.br

Resumo: O estudo reflete sobre os significados das Comissões Próprias de Avaliação (CPA) criadas como estratégia possibilitadora de processos de avaliação institucional participativa. Busca estabelecer comparações a partir da implementação desta estratégia em escolas de uma rede municipal de ensino a partir de uma releitura do modelo utilizado no SINAES. Os resultados confirmam a importância da CPA como instância que promove o encontro dos atores sociais nos espaços coletivos para buscarem o aprimoramento da qualidade de ensino de forma organizada e plural. Apontam-se as vantagens do uso das CPAs no ensino fundamental pela proximidade dos processos de avaliação dos atores internos e externos à escola.

Palavras-chave: Avaliação institucional. Educação superior. Ensino fundamental. Participação. CPA.

SELF EVALUATION COMISSION: SIMILARITIES AND DIFFERENCES IN THE USE OF STRATEGY IN HIGHER EDUCATION AND ELEMENTARY SCHOOL EDUCATION

Abstract: The study aims to think about the meaning of the Self Evaluation Commissions created as a strategy that permits institutional self- evaluation processes in higher education. It aims to establish comparisons from a rereading of the model used by SINAES in Brazil higher education. The results confirm the importance of the Self Evaluation Commissions as an instance that promotes the meeting of the social actors in collective spaces to search for the improvement of learning quality in an organized and plural form. The advantages of the use of such commissions in fundamental school education are appointed by the proximity of the self evaluation processes of the internal and external actors related to the school.

Key words: Institutional evaluation. Higher education. Fundamental school. Participation, Self Evaluation Commission.

\section{AS MOTIVAÇÕES DO ESTUDO}

A lei 10861 de 14 de abril de 2004 que instituiu o Sistema Nacional de Avaliação da Educação Superior (SINAES) expressa acordos firmados em campo fortemente disputado posto que repercutem nos rumos das políticas públicas de educação e de avaliação por meio da afirmação de determinada visão de qualidade.

Assentado nos princípios da globalidade, da continuidade, da historicidade, da legitimidade técnica e política dos processos avaliativos e negando a cultura 
da classificação e ranqueamento assim como o uso de recompensas ou punições fortemente presentes em processos avaliatórios, o SINAES - cujos pressupostos teóricos foram em boa parte tributários da experiência do Programa de Avaliação Institucional das Universidades Brasileiras (PAIUB) - pautou-se em concepção de avaliação formativa e processual a partir da qual o Estado exerceria também responsabilidade regulatória visando à promoção da qualidade da educação superior brasileira.

A indissociabilidade entre processo/produto; a articulação do olhar interno e externo; o diálogo entre as várias dimensões e categorias e a agregação de aspectos qualitativos a processos historicamente centrados em números constituem-se bases orientadoras do modelo que intenciona afetar o paradigma comumente presente nos processos de avaliação da qualidade educacional e promover uma cultura avaliativa mais conseqüente sob o ponto de vista da relevância social (DIAS SOBRINHO, 2010).

Entendido como política mista de regulação e avaliação das IES, a arquitetura do formato avaliativo do SINAES convocava a participação plural dos atores envolvidos no processo de qualificação do ensino de graduação do país. Esta participação sustentava-se por meio de ações gestadas no nível de Comissões Próprias de Avaliação (CPAs) instaladas em cada IES cuja composição envolvia representação dos professores, dos estudantes, do corpo técnico administrativo e da sociedade civil.

As CPAs foram concebidas como estratégia agregadora das forças sociais existentes no cenário das IES para ações de diagnóstico situacional e eleição de prioridades com vistas à proposição de encaminhamentos sintonizados com a imagem de futuro institucional desejada e com aderência às Diretrizes Curriculares Nacionais (DCN). Embora não tivessem poder decisório, as CPAs restauravam na cena avaliativa o principio da legitimidade política para identificar, sistematizar e encaminhar às instâncias colegiadas evidências tanto das potências como das fragilidades encontradas nos projetos pedagógicos (PP) institucionais e de cursos para apoiar os processos de tomada de decisão ligados ao aprimoramento da qualidade do ensino. Uma concepção de qualidade comprometida com os interesses da sociedade e que relembrava o significado da missão de cada IES no cumprimento de seu papel social.

Buscava-se a aproximação dos diferentes segmentos sociais presentes e contraditoriamente dispersos na cena universitária visando seu envolvimento com o processo da auto-avaliação institucional convocando-os a leituras multifacetadas sobre o significado da qualidade buscada nos cursos de modo a gerar ambiência mais propicia à formulação de um pacto de qualidade negociado 
(BONDIOLI, 2005) que fizesse sentido aos atores e que os induzisse de alguma forma ao comprometimento social.

O foco do trabalho das CPAs voltava-se ao fortalecimento de reflexões fundamentadas nos dados gerados pela avaliação que depois eram sistematizadas em relatórios e atendiam a dupla finalidade: instrumentalizar e subsidiar o processo decisório local, colocando-o a serviço do PP institucional e, responder às demandas da avaliação externa e ao processo de regulação estatal que buscava induzir, pelo menos no plano discursivo uma qualidade detentora de pertinência social.

A implantação das CPAs nas IES na forma como foram concebidas cumpriam papel fomentador do trabalho coletivo envolvendo a comunidade universitária visando potencializar ações de aprimoramento do PP tomando como referência a avaliação interna e o processo de autoconhecimento local realizando a relocalização da avaliação no dizer de Canário (2006). Para tal, as CPAs não deveriam ser compreendidas e menos ainda ser convertidas em espaços burocráticos de compilação de informações.

Ainda que sua constituição fosse uma exigência da política de regulação e houvesse indicativos do que precisaria ser feito e prazos que parametrizavam os encaminhamentos ao órgão central, o processo de trabalho da CPA era aberto e buscava respeitar a autonomia e a cultura institucional.

Cabe destacar que a Lei do SINAES constituía-se uma avaliação de sistema (nível macro da avaliação) orientadora de políticas públicas de educação o que implicava certa uniformidade na condução do processo. Deriva daí que o formato avaliativo disponibilizado para orientar as IES espelhava concepções de educação superior e de avaliação perceptíveis na seleção dos indicadores, categorias e dimensões presentes nos instrumentos de avaliação externa o que confirma a impossibilidade de neutralidade no campo avaliatório. Estes instrumentos utilizados para fins de credenciamento, de autorização e de reconhecimento de cursos comportavam a agregação de aspectos qualitativos que pretendiam ajudar a compreender e desvelar a realidade institucional e o movimento próprio na direção da qualificação de seu projeto pedagógico (PP) e ainda orientar o diálogo com os avaliadores externos quando da visita in loco. Esta estratégia tida como de alto valor formativo e nuclear para recuperação da credibilidade da avaliação como instrumento de gestão tanto local como nacional exigiu uma retomada do processo de seleção de avaliadores de modo a que os princípios do SINAES fossem postos em prática. Estes avaliadores uma vez selecionados deviam participar de uma capacitação subsidiada pelo MEC/INEP que envolvia a discussão dos significados dos referenciais do modelo avaliativo 
para além da aprendizagem correta de aplicação dos instrumentos. Deriva daí a criação do Banco Único de Avaliadores a partir do qual a avaliação externa se realizava tanto quanto possível de modo coerente com os princípios do SINAES. Estes avaliadores, in loco observavam, dialogavam e compilavam evidências concretas do trabalho institucional realizado que subsidiavam a posteriori tanto as ações de regulação sob responsabilidade do sistema quanto às ações locais. O diálogo avaliativo realizado nas IES/ cursos permitia compreender e problematizar a realidade e gerava relatório que transcendia o reducionismo de um check list agregando-lhe sentidos.

Sendo os referenciais teóricos do SINAES bem como suas bases operacionais de conhecimento públicos, as IES tinham parâmetros que norteavam os trabalhos das CPAs, porém nada impedia que estas, a depender do nível de auto-organização e de politização existente e da maneira como pensada sua inserção da vida institucional, pudessem planejar estratégias de ação visando extrair da avaliação seus melhores usos pedagógicos e políticos. O pressuposto era que estas comissões atuassem de modo integrado às instâncias oficiais já existentes subsidiando-lhes as decisões de cunho acadêmico-administrativo e com margem para processar leituras criticas da realidade institucional (RISTOFF; ALMEIDA JUNIOR, 2005).

Se a base teórica do SINAES não deixava dúvidas acerca do paradigma de avaliação em que se ancorava, a implementação do modelo não ocorreu sem contradições derivadas do embate de interesses que cerca de forma recorrente a questão da avaliação.

$\mathrm{Na}$ prática o que se viu foi certo desvio ou esvaziamento da proposta das CPAs que mais pareciam cumprir papel de compilação de dados para envio protocolar ao MEC/INEP (perfil técnico burocrático), furtando-se ao trabalho de orquestração da comunidade universitária para a interpretação destes dados referenciando-os ao projeto institucional. Isso talvez explique o baixo poder de ingerência destas sobre as decisões institucionais e paradoxalmente o alto interesse de controle sobre a natureza de seu processo de trabalho por parte de alguns dirigentes/mantenedores.

Essa tendência de paralelismo às instâncias colegiadas despotencializou a ação política transformadora das CPAs e dos processos internos por estas deflagrados nas IES. Observou-se, no entanto, também respostas institucionais mais potentes à extração de bons usos da avaliação quando os processos de trabalho das CPAs devidamente apoiados pela administração local conseguiram superar esse reducionismo na forma de implementar a proposta do SINAES. 
Baseados nos pressupostos ético-epistemológicos do SINAES e acreditando na CPA como estratégia potente para reorganização dos atores sociais, apesar dos limites já sinalizados observados na forma de implementação da proposta na educação superior optamos por replicar esta experiência na educação básica a partir de uma releitura do processo vivido nas IES.

Nossa hipótese foi a de que em uma rede de ensino cujo projeto pauta-se nos princípios da gestão democrática, o desenvolvimento de processos de avaliação precisa ser igualmente democrático. Processos democráticos são por natureza participativos e esta participação qualificada pelo exercício contínuo e reflexivo propicia aos atores implicados, oportunidades de interferir no pacto de qualidade negociando percepções e expectativas de modo a construir consensos sólidos e eticamente comprometidos com uma qualidade socialmente pertinente. A recomposição da coerência entre teoria e prática e entre discurso e ação no campo avaliatório nos pareceu ser favorecida pela assunção do ideário do SINAES e de uma de suas estratégias operacionais, qual seja a CPA.

Esta lógica serviu de inspiração à política de Avaliação Institucional Participativa (AIP) desenvolvida em 44 escolas de ensino fundamental da Secretaria Municipal de Educação (SME) de Campinas a partir de 2008 e implementada com o apoio de pesquisadores da universidade pública local. Foi concebida a partir da releitura crítica das contradições do SINAES e se ancora na versão inicial do projeto, posto que muitas das alterações inseridas ao longo do tempo e que geraram várias reedições da lei, parecem hoje se afastar das bases teóricas com que nos identificávamos (SORDI; SOUZA, 2009).

Este trabalho pretende, pois examinar a implementação da estratégia da CPA no cenário das escolas envolvidas no projeto de AIP desta rede de ensino identificando as similaridades e dessemelhanças em relação à experiência desenvolvida na política da educação superior. Trata-se de avaliar a potência das CPAs como espaço organizador da participação da comunidade no PP das escolas e como estratégia que auxilia a recuperação da perspectiva integralizadora da avaliação da qualidade das escolas pela introdução do principio da negociação entre os concernidos no processo.

\section{A ESTRATÉGIA DAS CPAS NAS ESCOLAS DE ENSINO FUNDAMENTAL: SIMILARIDADES E DESSEMELHANÇAS COM A EDUCAÇÃO SUPERIOR}

Observamos que semelhantemente à experiência na educação superior, a proposição das CPAs nesta rede de ensino, não implicou mudanças de vulto na 
estrutura vigente. Ou seja, no caso das IES, muitas já desenvolviam trabalhos de avaliação institucional participativa e então trataram de atualizar o modus operandi nos termos do SINAES. Naquelas IES em que a cultura de avaliação não estava desenvolvida, a implantação da CPA pareceu ocorrer mais como resposta à regulação sistêmica do que por valorização dos princípios da participação presentes no modelo SINAES e concretizados via CPA. Daí a certa artificialização no uso da estratégia da CPA foi um passo.

Nas escolas municipais a instalação da CPA ocorreu valendo-se de estrutura já existente, no caso o Conselho de Escola, a quem cabia indicar os membros da CPA e aprovar-lhe o plano de trabalho. Ao eleger um dos membros da equipe gestora como articulador (o Orientador Pedagógico) o sistema valeu-se de ator especialmente envolvido na gestão do trabalho pedagógico e como tal familiarizado com a importância da avaliação em suas dimensões e interfaces. Implicado diretamente na coordenação do trabalho coletivo na escola, a política da AIP apenas explicitou ao OP (entendido como membro da equipe gestora), a necessidade de incorporação dos demais atores sociais no monitoramento do PP, quando esta participação ainda não estava assegurada. No caso da educação superior, a coordenação dos trabalhos era objeto de portaria da reitoria e atendia a critérios políticos nem sempre acompanhados de legitimidade. Parece que a intencionalidade assumida pela SME na indicação do ator responsável pela condução dos trabalhos mostrou-se adequada aos fins perseguidos.

Uma diferença marcante na etapa de instalação das CPAs foi o tempo usado para atendimento da resolução e os dispositivos regulatórios acionados para assegurar a adesão à política de AIP que no ensino fundamental se mostrou mais lento.

$\mathrm{Na}$ educação superior, por força dos prazos e formas de encaminhamento estipulados pelo sistema assumindo seu papel de regulação e desfrutando do amparo legal obtido pela aprovação da Lei do SINAES, observou-se que a resposta das IES foi plenamente atendida embora no dia a dia como já referido tenha se percebido que a adesão mostrou-se mais formal do que real.

A resposta das escolas municipais em relação à implantação das CPAs ocorreu de modo diferenciado, ou seja, nem todas responderam prontamente à determinação alegando inúmeros dificultadores. Ora a ausência do Orientador Pedagógico para deflagrar o processo, ora a demora na constituição do Conselho de Escola, ora a dificuldade de compatibilização de horários dos eventuais interessados.

A política de avaliação da qualidade das escolas nesta rede revelou-se tímida sob o ponto de vista da regulação em nosso entendimento. Os propositores 
da política de AIP na SME careciam de maior familiaridade teórica com a proposta necessitando formar-se no próprio processo. Isso afetou os tempos e as estratégias de implementação que iam sendo aprendidas e negociadas pari passu. A inexistência de base legal formal instigou movimento de resistência em alguns atores que pareciam se negar a cumprir a política pública adotada. Não há como desconsiderar que algumas vezes estas resistências não se referiam apenas ao modelo proposto e poderiam ser indícios de resistência a qualquer tipo de avaliação.

A proximidade territorial dos atores das escolas e as relações informais com o poder central (SME) parece também ter afetado o ritmo da adesão atrasando a instalação e ou inibindo mecanismos de supervisão do cumprimento da política. Observou-se que a cultura da rede municipal de ensino propiciou ainda a própria contestação da política tida para alguns como autoritária (de cima para baixo). Cabe ressaltar que a discussão sobre as bases teóricas do modelo já vinham sendo realizadas desde 2002 e estavam socializadas naquilo que se denominou "Carta de Princípios da Avaliação" disponíveis no site da Secretaria Municipal (FREITAS; SORDI; MALAVAZI; FREITAS, H., 2004). O que se alterou foi a decisão política de buscar forma de implementação prática dos princípios buscando superar a descontinuidade dos trabalhos pelo aproveitamento das condições políticas favoráveis no momento. Assim a avaliação foi tomada como política de governo visando forma de regulação que se ancorasse em princípios mais abrangentes do que aqueles ligados sobremaneira aos resultados de desempenho dos estudantes.

Observou-se ainda certa desconfiança dos atores em relação à política de AIP. Embora pleiteassem titularidade nos processos e negassem decisões vindas "de cima para baixo", paradoxalmente demonstravam estranheza ao serem surpreendidos pelo caráter aberto e inacabado da política avaliativa que lhes ocasionava alguma insegurança relativa aos desdobramentos práticos do tipo "como é para fazer?"

A forma de administração descentralizada existente nesta rede de ensino que se organiza em cinco (5) Núcleos de Ação Educativa Descentralizada (NAEDs) com a função de articular o trabalho das escolas ao Departamento Pedagógico da SME repercutiu de alguma forma no processo comunicacional, ou seja, os fluxos de informação ora favoreciam a circularidade das trocas e a produção de novos sentidos topo/base ora produziam curtos circuitos importantes a depender do modo como os atores compreendiam seu papel na política ou dispunham de conhecimento sobre ela. $\mathrm{O}$ fato é que a proximidade territorial entre estas instâncias interferia de algum modo na política de avaliação comprovando a 
importância da municipalização da avaliação defendida por Freitas, Sordi, Malavazi, Freitas, H. (2009) dificulta posturas de indiferença aos resultados da avaliação ampliando a produção de sentidos destes decorrentes.

Esta característica não se observou no SINAES, pois o coração da política de avaliação estava centralizado em Brasília, distante, portanto do cotidiano das IES. Atendidas as exigências formais do modelo regulatório e ocorridas as avaliações in loco, as IES em tese poderiam escolher entre o uso formativo ou somativo da avaliação com baixo poder de pressão da comunidade interna.

O projeto de AIP na rede municipal constituindo-se como política de governo e não de Estado, precisou intensificar o cuidado com a fase de sensibilização das escolas. Igualmente precisou cuidar da capacitação dos atores visando atenuar as resistências e construir condições políticas para sustentar a proposta inovadora evitando fosse ela reduzida a uma mera novidade fadada ao esquecimento dada a habitual descontinuidade das políticas públicas face às mudanças de governo. Disso derivou investimento claro na formação dos OPs e destinação de verbas para garantir participação dos professores nas reuniões de CPAs. Igualmente o planejamento de uma série de eventos de cunho mais amplo promovidos pela SME ajudou a ativar o entendimento dos diferentes segmentos envolvidos no trabalho de avaliação de modo a alicerçar as condições do pacto de qualidade negociado pretendido. Este conjunto de estratégias consumiu tempo que para alguns deveria ser gasto avaliando-se a qualidade. No entanto, o que se viu foi a decisão política de construir uma cultura avaliativa marcada pela recuperação da confiança no processo de avaliação e pelo resgate do prazer da participação na vida da escola.

Tais opções implicaram maior lentidão na obtenção de "resultados práticos" atribuídos à avaliação, porém ajudaram a potencializar o envolvimento dos segmentos apostando em sua sensibilização e engajamento diuturno para gerar bases para o estabelecimento do controle social sobre os rumos do projeto de AIP.

Curiosamente destacamos que na educação superior a universalização da instituição das CPAs nas IES não repercutiu necessariamente na intensificação e qualificação da participação no projeto de autoconhecimento institucional. À exceção daqueles cursos/IES que já tinham tido envolvimento anterior com as bases teóricas do PAIUB e, por conseguinte possuíam algum repertório em processos de avaliação participativa, os resultados das CPAs ficaram aquém das expectativas da proposta e tiveram sua centralidade na orquestração dos atores sociais bastante reduzida dadas às formas de controle que sofreram e que reduziram o protagonismo presumido no ideário do SINAES. 
A repercussão da proposta da CPA no nível das escolas de ensino fundamental da SME de Campinas mostrou maior potencialidade para reunir a comunidade interna visando aprofundar o debate sobre a qualidade da escola. Ainda que os resultados desejados não tenham sido observados na totalidade das escolas, avanços mais contundentes se fizeram notar naquelas realidades que já possuíam uma cultura de trabalho coletivo e indícios de valorização da participação na construção do projeto pedagógico. Estas desenvolveram diferenciados processos de trabalho em nível das CPAs sendo que alguns destes já incluíam ações de planejamento e de avaliação o que interferiu positivamente na resposta à demanda da SME com prontidão na instalação das CPAs e mais ainda na disposição de fixar um cronograma de encontros que permitisse a participação dos vários segmentos.

Nos espaços onde a ambiência democrática parecia estar mais introjetada, o trabalho das CPAs fluiu melhor. Não demorou a que o OP deixasse de manifestar sua "preocupação com a introdução de mais uma novidade imposta de cima para baixo" ou "desconfiança de que a idéia logo seria abandonada, pois toda vez que muda governo, muda alguma coisa" e passasse a revelar "agora entendi o que é esta tal de avaliação institucional. A gente já fazia, mas não com este nome" ou "se é para esta finalidade, penso que a CPA veio dar força para aquilo que a gente já fazia".

Outras escolas responderam ao comando central, porém de modo formal, quase burocrático. Houve casos de escolas que referiram não ter conseguido montar suas CPAs alegando dificuldades ligadas ao desinteresse de alguns segmentos ou inexistência de condição para consensuar horários comuns. $\mathrm{Cu}$ riosamente quando a SME acionou estrategicamente eventos de socialização das experiências vivenciadas (incluindo a produção de pôsteres) pretendendo cartografar a política de AIP, o que se viu foi que todas as escolas se fizeram presentes indicando a existência das CPAs com representantes de cada segmento (ainda que o segmento família aparecesse em menor número).

Se compararmos com a experiência de constituição das CPAs na educação superior, observamos que as respostas das instituições de ensino foram igualmente distintas. Predominou uma resposta formal à exigência do MEC/ INEP para efeitos de atender ao mecanismo regulatório. O que se viu foi que muitas CPAs (IES?) apenas documentalmente respondiam ao indicado pela Lei do SINAES, ou seja, as reuniões se circunscreviam a alguns atores com exclusão formal ou informal de outros tantos. Alegava-se igualmente a ausência de tempo comum, a inexistência de interesse e que frente à urgência de cumprimento dos prazos, alguém tinha que tomar a frente e realizar o trabalho 
em nome do coletivo. Estudos apontam a precária socialização dos resultados da avaliação assim como indicam uma participação da comunidade mais ligada ao preenchimento dos formulários (LEITE, 2008).

A pergunta que se impõe é se o problema está na estratégia da CPA ou no baixo apreço institucional ao principio da participação plural? Cabe ainda indagar se pressionados pelo imediatismo dos resultados ou meio que acostumados a decisões rápidas que dispensam ou denegam a importância da multiplicidade de visões sobre o mesmo fenômeno, se há espaços para projetos de AIP em nossas realidades educacionais tal como estas se organizam e naturalizam seu cotidiano de trabalho.

Prosseguindo na descrição de semelhanças e distinções na forma de conduzir os trabalhos das CPAs, parece-nos que as escolas levam vantagens em relação às universidades na forma de uso do espaço da CPA, sobretudo se já estiverem exercitando processo de trabalho que leve em conta as relações da escola com seu entorno. O porte da escola favorece o acompanhamento dos trabalhos da CPA e assim oportuniza certo controle social sobre o processo de qualificação da escola. Observou-se que a proximidade territorial da escola com a comunidade local favorece a inclusão dos segmentos não profissionais na gestão do PP da escola e na sua avaliação. No entanto, a ausência da cultura efetiva de participação afeta o interesse pela adesão assim como a assertividade desses atores na negociação das prioridades do PP.

Quanto mais os espaços de trabalho coletivo contemplarem as múltiplas vozes e interesses dos atores internos e externos da escola, mais potentes serão os processos de negociação que estes poderão produzir. Mehry (2005) lembra que os coletivos organizados já sabem que sua escolha de organização expressa modos de produzir educação.

Uma semelhança observada em ambas as experiências encontra-se na contestação da necessidade de se instituir uma CPA entendendo-a como nova forma de fazer o mesmo trabalho (ou quem sabe, de não o fazer).

Observaram-se reações apontando que a proposição da CPA poderia ser forma de esvaziamento do Conselho de escola pela duplicação de espaços e superposição de papéis e responsabilidades. Na educação superior, alguns lembraram que já existiam instâncias responsáveis pela avaliação atuando junto às Pró-Reitorias ainda que não comportassem nem a participação dos múltiplos atores institucionais. Na experiência da SME, quando da concepção do formato avaliativo lembrou-se a burocratização que perpassava as reuniões dos conselhos de escola o que poderia relegar papel menos expressivo ao processo de avaliação institucional que se engendrava timidamente como política pública. 
Não pareceu suficiente aos propositores da política, atendendo aos argumentos dos pesquisadores que assessoravam o processo, confiarem na mera inserção do tema "avaliação" como item de pauta do colegiado concorrendo com as lógicas já instituídas. O que se buscava na agenda política era induzir a relocalização da avaliação nas escolas (CANÁRIO, 2006) ampliando a discussão sobre a qualidade educacional para formulação coletiva de indicadores de qualidade próprios a serem agregados aos indicadores externos ligados ao desempenho dos estudantes e taxas de aprovação, retenção, evasão (fluxo) entre outros com subseqüente fixação de metas e demandas bidirecionais devidamente negociadas.

Caberia à CPA devidamente coordenada pelo OP de cada escola desenvolverse na capacidade de identificação plural dos problemas (participação dos vários atores com múltiplas visões e expectativas) visando posterior negociação das prioridades (definidas para o ano letivo e renovadas periodicamente) e fixação de metas de cunho qualiquantitativo permitindo monitoramento da proposta (principio da transparência e do controle social).

No caso das IES, observa-se movimento interessante quando do surgimento do SINAES. Algumas destituem as comissões já existentes (e em alguns casos atuantes) para se ajustarem à lei enquanto outros criam suas CPAs para que funcionem do jeito que lhes convém sem atentarem aos avanços implícitos na proposta do SINAES seja quando integra novos atores sociais ao processo ou quando amplia as dimensões do processo avaliativo avançando na direção de um modelo de cunho menos utilitarista e mais orientado pelo eixo da qualidade social.

Ainda que a experiência das CPAs nas escolas da rede de Campinas não nos permita ainda fazer afirmações mais contundentes acerca de sua repercussão na qualificação do projeto da escola parece válido sinalizar que algumas decisões tomadas a partir da releitura da experiência do SINAES mostram-se potentes para o fortalecimento do protagonismo dos atores locais (sobretudo os da CPAs). Diferentemente do observado nas IES, os membros das CPAs nas escolas desfrutam de algum prestigio na comunidade escolar, tem visibilidade política e em alguns casos revelam bom poder de organização e capacidade argumentativa frente ao poder central como se observou em reunião convocada pelo secretário municipal de educação e os integrantes das CPAs das escolas com o intuito de completar o ciclo de negociação iniciado nas escolas e que agora inseria o poder central no diálogo e no processo decisório.

Nas IES não se observou grande visibilidade das CPAs sendo-lhes mais freqüentemente atribuído o papel de coadjuvante na política de avaliação institucional, auxiliando os cursos a organizar e disponibilizar as informações 
para os avaliadores externos cumprirem sua agenda de trabalho e a IES assim poder ser certificada.

O quadro I busca sistematizar os achados e suas marcas distintivas e nos ajudam a refletir sobre os significados e as repercussões da experiência das CPAs dentro de processos de AIP.

\section{Quadro I - Similaridades e dessemelhanças no uso das CPAs nos modelos de AIP na educação superior e em escolas de ensino fundamental, 2010}

\begin{tabular}{|l|l|l|}
\hline & CPA/ Educação Superior & CPA/Escolas da SME Campinas \\
\hline Designação & Reitor & Conselho de Escola \\
\hline $\begin{array}{l}\text { Coordenação dos } \\
\text { trabalhos }\end{array}$ & Nomeação do reitor & $\begin{array}{l}\text { Orientador Pedagógico da escola } \\
\text { (membro nato) }\end{array}$ \\
\hline Base regulatória externa & DCNs, LDB, SINAES & IDEB \\
\hline Base regulatória interna & PDI e PPI & $\begin{array}{l}\text { PP e indicadores de qualidade da } \\
\text { SME }\end{array}$ \\
\hline Atores previstos & $\begin{array}{l}\text { Representantes de todos os } \\
\text { segmentos incluindo } \\
\text { sociedade civil }\end{array}$ & $\begin{array}{l}\text { Representantes de todos os } \\
\text { segmentos incluindo famílias }\end{array}$ \\
\hline $\begin{array}{l}\text { Sistematização do } \\
\text { Plano de Avaliação }\end{array}$ & Obedece a ciclo MEC/INEP & $\begin{array}{l}\text { Formulação anual consoante à } \\
\text { entrega do PP }\end{array}$ \\
\hline $\begin{array}{l}\text { Periodicidade dos } \\
\text { encontros CPA }\end{array}$ & $\begin{array}{l}\text { A critério do grupo, mas } \\
\text { fortemente influenciado pelo } \\
\text { ciclo MEC/INEP }\end{array}$ & $\begin{array}{l}\text { A critério do grupo, mas com } \\
\text { indicação de pelo menos uma } \\
\text { reunião mensal }\end{array}$ \\
\hline $\begin{array}{l}\text { Nível de autonomia da } \\
\text { CPA }\end{array}$ & Pequeno e condicionado & Grande e progressivo \\
\hline $\begin{array}{l}\text { Empowerment dos } \\
\text { atores }\end{array}$ & Fraco & Médio/forte \\
\hline Visibilidade local & Média ou diluída & Alta \\
\hline Legitimidade política & Relativa & Potencialmente boa \\
\hline Potencial transformador & Fraco & Alto \\
\hline $\begin{array}{l}\text { Concepção teórica de } \\
\text { avaliação do modelo }\end{array}$ & Formativa & Formativa \\
\hline $\begin{array}{l}\text { Concepção de avaliação } \\
\text { predominante na forma } \\
\text { de operacionalização }\end{array}$ & Técnico burocrático & $\begin{array}{l}\text { Mista (formativa e técnico } \\
\text { burocrática) }\end{array}$ \\
\hline $\begin{array}{l}\text { Valorização dos } \\
\text { espaços coletivos } \\
\text { institucionais }\end{array}$ & Precária ou inexistente & Presente \\
\hline Diálogo topo base & Intermediado & Direto \\
\hline
\end{tabular}




\section{CPA: MEIO OU FIM?}

A experiência de implantação das CPAs nas escolas de ensino fundamental da SME concebida como estratégia ordenadora do processo de AIP a partir dos referenciais do SINAES mostrou-se importante para reacender o debate sobre as possibilidades e impossibilidades técnico-politicas presentes em modelos de avaliação pretensamente democráticos e participativos.

Insistimos na tese de que as CPAs podem constituir-se como espaços favorecedores do encontro dos atores sociais envolvidos na qualificação do projeto da escola estimulando sua organização em torno de causas comuns. Disso deriva a tensão saudável entre interesses privados e coletivos e a CPA pode funcionar à semelhança da ágora citada por Bauman (2000, p. 11) como

esse espaço nem privado nem público, porém mais precisamente público e privado ao mesmo tempo. Espaço onde os problemas particulares se encontram de modo significativo - isto é, não apenas para extrair prazeres narcisísticos ou buscar alguma terapia através da exibição pública, mas para procurar coletivamente alavancas controladas e poderosas o bastante para tirar os indivíduos da miséria sofrida em particular; espaço em que as idéias podem nascer e tomar forma como "bem público", "sociedade justa" ou "valores partilhados".

$\mathrm{Na}$ educação superior, parece que as CPAs rapidamente se amoldaram ao ritmo institucional, sobretudo pela inclusão formal de atores externos sem que se lhes garantisse a condição de envolvimento nos trabalhos. Rompeu-se assim a idéia de participação plural (e, por conseguinte subtraiu-se a potência da ágora) o que dificultou o engajamento no trabalho de avaliação e a ampliação da confiança dos atores neste processo. A experiência das CPAs nas escolas de ensino fundamental é neste aspecto favorecida pela proximidade territorial dos atores. Esta potencializa a sensação de pertencimento ao PP da escola e desta deriva certa implicação com os rumos da escola pública e com a aprendizagem das crianças. Existindo instância que convoca a participação plural e que acolhe os atores sociais em suas formas peculiares de se manifestar sobre qualidade da escola pública, amplia-se a possibilidade de que os encontros possam gerar acordos que produzam ações e intervenções socialmente pertinentes e orientadas pelo interesse coletivo.

Disso decorre que as CPAs precisam ser vistas como meios favorecedores para o exercício de uma avaliação maiúscula, tanto na perspectiva de sua abrangência como de sua intencionalidade emancipadora. Uma CPA pode se constituir germe possibilitador do (re) encontro dos atores sociais para que 
voltem a pensar sobre o bem público. Não se resolve a questão da avaliação apenas com a implantação de uma CPA, mas na certa esta estratégia auxilia a colocar a avaliação novamente como algo a ser examinado pelos atores internos e externos da escola, devolvendo-lhes titularidade sobre o processo e auxiliando-os a desenvolver assertividade para participar do pacto de qualidade negociado.

$\mathrm{Na}$ educação superior, onde primeiro se exercitou a estratégia da CPA, observamos que a potência transformadora implícita na proposta foi gradativamente subsumida pelas pressões cotidianas para produção de dados para o sistema. Nas escolas deste estudo, entendemos que as CPAs têm funcionado como meio para atingir um objetivo maior, qual seja fortalecer os atores da escola para que exerçam seu protagonismo e ajudem a construir qualidade na escola pública. Entendidas como meio e não sendo confundidas como único espaço onde se avalia a qualidade da escola, mas como o espaço que organiza as diferentes vozes da escola para avaliarem-se mutuamente referenciadas pelo PP, parece que as CPAs têm cumprido seu papel.

Entendemos que os caminhos e descaminhos do SINAES, sobretudo no que tange ao uso das CPAs possibilitou-nos exercitar o sentido formativo da avaliação, tornando-se fonte inspiradora para retomadas e redesenhos com vistas ao aprimoramento da proposta ou do uso que foi feito das idéias apresentadas pelo SINAES. Parece-nos que não se trata de mera transferência de tecnologia da educação superior para a educação básica. Mas de outra interpretação e esforço de concretização de um modelo que por representar importante avanço no campo da avaliação não pode ser desperdiçado e nem simplificado ao ponto de perder sua essência.

\section{REFERÊNCIAS}

BAUMAN, Zigmund. Em busca da política. Rio de Janeiro: Jorge Zahar, 2000 .

BONDIOLI, Anna. O projeto pedagógico da creche e sua avaliação.

Campinas: Autores Associados, 2005.

CANARIO, Rui. A escola tem futuro? Das promessas às incertezas. Porto Alegre: Artmed, 2006. 
DIAS SOBRINHO, José. Avaliação e transformações da educação superior brasileira (1995- 2009) do provão ao SINAES. Avaliação, Campinas; Sorocaba, SP, v. 15, n. 1, p. 195-224, mar. 2010.

FREITAS, Luiz Carlos; SORDI, Mara Regina Lemes; MALAVASI, Marcia; FREITAS, Helena. Dialética da inclusão e da exclusão: por uma qualidade negociada e emancipadora nas escolas In: GERALDI, Corinta et al. Escola viva. Campinas: Mercado das Letras, 2004.

FREITAS, Luiz Carlos; SORDI, Mara Regina Lemes; MALAVASI, Marcia; FREITAS, Helena. Avaliação educacional: caminhando pela contramão. Rio de Janeiro: Vozes, 2009.

LEITE, Denise. Ameaças pós rankings sobrevivências das CPAs e da autoavaliação. Avaliação, Campinas; Sorocaba, SP, v. 13, n. 3, p. 833-840, nov. 2008.

SINAES. Da concepção à regulamentação. 5. ed. revisada e ampliada. Brasília: MEC/INEP, 2009.

MERHY, Emerson. Engravidando palavras: o caso da integralidade In: PINHEIRO, R.; MATTOS, R. A. Construção social da demanda. Direito à saúde. Trabalho em equipe. Participação e espaços públicos Rio de Janeiro: IMS/UERJ- CEPESC-ABRASCO, 2005.

RISTOFF, Dilvo; ALMEIDA JUNIOR, Vicente. Avaliação participativa, perspectivas e desafios. Brasília: INEP, 2005.

SORDI, Mara Regina Lemes; SOUZA, Eliana. A avaliação institucional como instância mediadora da qualidade da escola pública: a rede municipal de educação de Campinas como espaço de aprendizagem. Campinas: Millenium, 2009. 